\title{
Correlation of Cervical Smear Cytology and
}

\section{Histopathology Findings From Van Yüzüncü Yıl}

\section{University Dursun Odabaş Medical Center İn Turkey}

\author{
Feyza Demir*, Remzi Erten, İbrahim Aras, İrfan Bayram \\ Van Yüzüncü Yll University, Faculty of Medicine, Department of Medical Pathology, Van, Turkey
}

\begin{abstract}
Papanicolaou cytology (Pap smear) is a screening technique recommended by World Health Organization (WHO), commonly used in the detection of precancerous lesions. This study aimed to compare the Pap smear results and the subsequent biopsy results in 258 patients diagnosed in our clinic to analyse their false-positive and false-negative rates and to discuss the outcomes in light of literature.

The study included Pap smear specimens archived for four years that had undergone histopatholojical diagnoses of cervical biopsy, conization, curettage, and/or histerectomy within the three months. In the retrospective analysis, cytological diagnosis and the histological diagnosis which had been established within the subsequent three months were compared and then the false-negative and false-positive rates were calculated.

In the cyto-histological comparison, the false-negative and false-positive rates independent of class ratio were $4,3 \%$ and $19 \%$, respectively. The sensitivity, selectivity, positive and negative predictive values were $69 \%, 98 \%, 89 \%$ and $93 \%$, respectively, excluding atypical classes of the cytologic diagnoses.

As can be seen in our results, the correlation between Pap smear and biopsy results in our patients displayed an unignorable inconsistency although it was not remarkably different from those reported in the literature. Such discrepancies, which are likely to be detected in the cyto-histopathological studies around the world and do not attenuate the value of cervical cytology despite being unignorable, indicate the necessity of screening schemes involving the combined and effective use of different techniques such as Human papillomavirus (HPV) tests, repeated smear examinations, colposcopic examination, and biopsy in patients diagnosed by cervical cytology.
\end{abstract}

Key Words: Cervical smear, histology, correlation

\section{Introduction}

Uterine cervical cancers, the 4th most common cancer in women worldwide, accounted for 6.6\% of all women's cancers in 2018 with 570,000 new case reports. Approximately $90 \%$ of the deaths occurred in low- and middle-income countries and it is known that mortality can be reduced with a comprehensive approach, including effective screening methods, early detection and prevention with vaccination for high-risk types of Human papillomavirus (HPV) (1).

Screening methods aim to detect precancerous changes in which high risk HPV plays a primary role in the etiology, which may turn into cancer if left untreated. Follow-up and treatment of a woman with abnormal changes in screening can prevent cancer development or treat cancer at an early stage. In this scale, screening methods recommended by the World Health Organization are cervical cytology, visual inspection of cervix uteri and HPV test mostly based on molecular methods (1).

Papanicolaou cytology (Pap smear) is widely used as a cervical cytology screening method for reasons such as the ability to detect precursor lesions of cervical cancer at high rates, low cost and feasibility of applicability (2).

Cervical cancers in which HPV plays a primary role in the etiology develops as a process that starts with viral effects and low-grade dysplasia in the epithelium and progresses to high-grade dysplasia and then invasive cancer. The BETHESDA classification as a nomenclature of epithelial cell anomalies in cervical cytology and the corresponding histological diagnoses, if any, are also shown in Table 1 (3). 
Table 1. 2014 BETHESDA System in cervical cytology reporting (3)

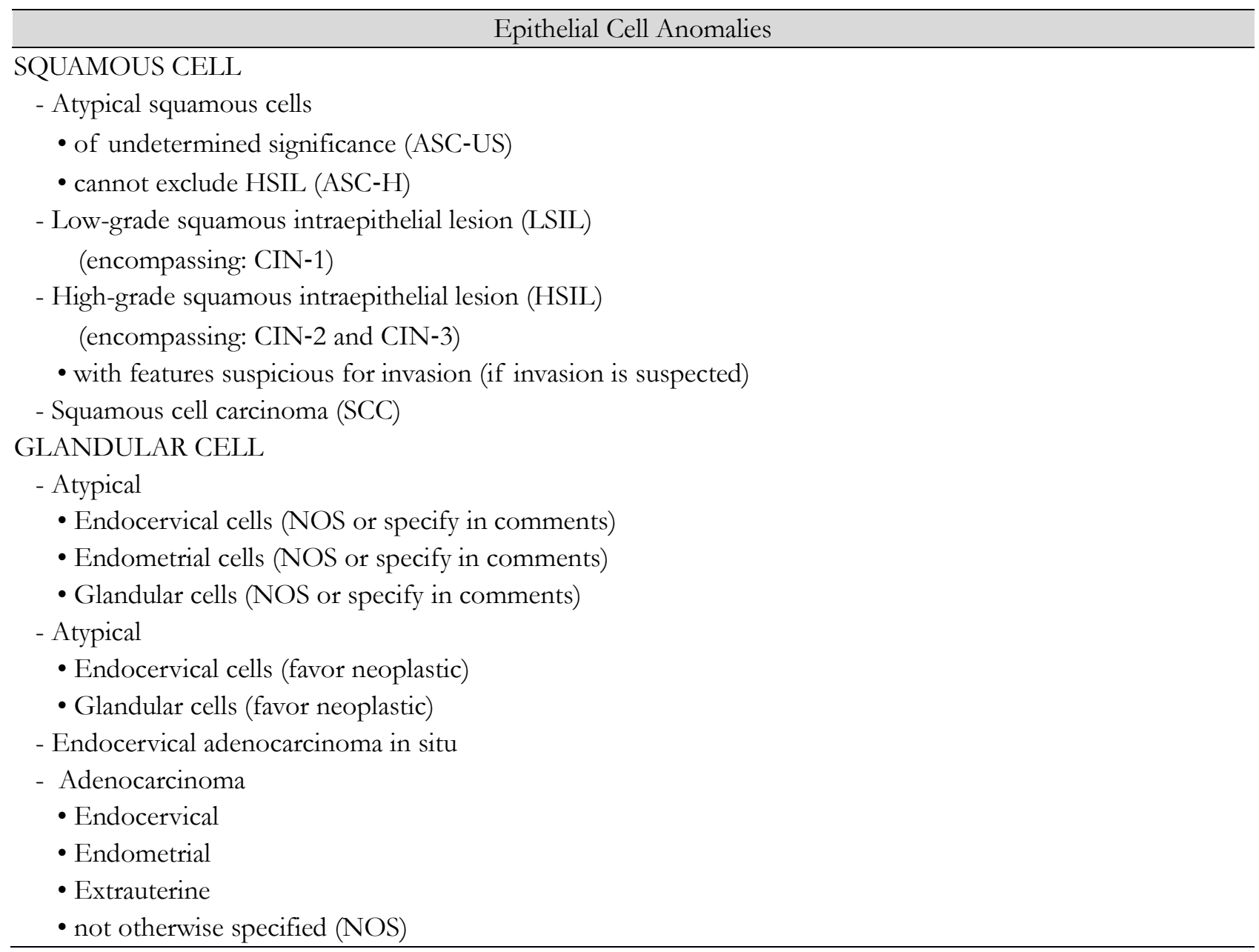

In our study, we aimed to see what Pap smear, which was diagnosed according to BETHESDA classification in our unit corresponded in their post-biopsy and determine false-positive and false-negative rates and to evaluate these results in the light of literature.

\section{Materials and Methods}

Ethical approval was obtained from the Van Yüzüncü Y1l University's ethical committee (Date: January 17, 2020; Decision no: 2020/01-04). The study was conducted in accordance with the principles of the Helsinki Declaration. A total of 258 patients, whose cervical biopsy, conization or curettage reports, including Pap smear test result at the latest from 3 months ago, were available in 4-year pathology archive of the Medical Pathology Department in Faculty of Medicine at Van Yüzüncü Y1l University were included in the study. The age range of 258 cases we included in our study is $21-76.182(70 \%)$ of histopathology reports were obtained from cervical biopsies, 56
$(22 \%)$ from conization materials, and the remaining $20(8 \%)$ belong to cervical curettage materials. The cytology reports were reports of smears obtained by conventional method. All patients included in the study were diagnosed in our department, and their cytological and histological materials were directed from the gynecology clinic of our university hospital to our unit. Pap smear diagnoses were made using BETHESDA classification system. Based on the BETHESDA 2014 classification (Table 1), the diagnoses of smears and biopsies were reviewed rapidly. All data of the patients in the pathology reports were retrospectively reviewed and cytology diagnoses and histopathologic diagnoses made immediately after were compared (Table 2). The patients, who were not previously diagnosed with cytological epithelial anomaly but were found to have anomalies based on subsequent histological report, were evaluated as false negative, and those with cytological epithelial anomalies, which were histologically benign, were evaluated as false positive. 
Statistical Analysis: After descriptive statistics for categorical variables were expressed in numerical and percentage values, the number of false negative and false positive cytology cases was compared to the number of all cases and thus, false negative and false positive rates were obtained (Table 3). Diagnostic test statistics were used to determine the performance of Pap smear screening test based on the histopathological diagnosis, which is recognized as the reference test for detecting the presence of lesion. As statistical criteria for the diagnostic test, sensitivity, selectivity, positive-negative predictive values and overall accuracy were calculated (Table 4). The SPSS version 20.0 (IBM Corp., Armonk, NY, USA) statistical software package was used for these procedures.

\section{Results}

Of the 258 cases (aged 21-76) included in the study, $168(65.1 \%)$ were diagnosed as benign cytology, while the remaining $90(34.9 \%)$ cases were diagnosed as positive cytology. The histopathology report indicated that nine $(5.4 \%)$ of 168 benign cytology results were cervical intraepithelial neoplasia1 (CIN-1), one $(0.6 \%)$ was squamous cell carcinoma (SCC) and the other one $(0.6 \%)$ was adenocarcinoma (ADC). The remaining 157 cases $(93.5 \%)$ had benign histopathologic diagnoses, consistent with their cytology. Based on the result of smear test, thirty $(76.9 \%)$ of 39 patients with atypical squamous cells of undetermined significance (ASC-US) were histopathologically benign, six $(15.4 \%)$ were CIN1 and three $(7.7 \%)$ were cervical intraepithelial neoplasia3 (CIN-3). From our smear test results diagnosed with atypical squamous cells - cannot exclude a high grade squamous intraepithelial lesion (ASC-H), fourteen $(63.6 \%)$ were diagnosed histopathologically as benign, three $(13.6 \%)$ as CIN-1, two $(9.1 \%)$ as cervical intraepithelial neoplasia2 (CIN-2), two (9.1\%) as CIN-3 and one $(4.5 \%)$ was diagnosed with SCC. In three $(23.1 \%)$ of our patients with low-grade squamous intraepithelial lesion (L-SIL), the histopathological results were benign, whereas eight patients (61.5\%) were reported as CIN-1 and two patients were reported as CIN-2. Histopathology results of our smear cases with high grade squamous intraepithelial lesions (H-SIL) showed that one (8.3\%) had CIN-1, eight (66.7\%) had CIN-3 and three $(25 \%)$ had SCC and there was no patient with benign histopathological report. One of the two cases $(50 \%)$ diagnosed with SCC smear was diagnosed histopathologically with CIN-3 and the other $(50 \%)$ with SCC. The histopathological diagnosis of two patients with atypical glandular cell (AGUS) smear diagnosis was benign $(100 \%)$. Finally, the ratio of all atypical squamous cell (ASC) cases included in the cytological diagnoses to all squamous intraepithelial lesions (SIL) in the cytological diagnoses was 2.52 in 63/25 patients. The numerical and percentage values of all cytohistopathological comparisons are also presented in Table 2.

The cases with atypical cytology (ASC-US, ASC-H and AGC) were included in false or true positive cases and the false positive rate was found to be $4.3 \%$ and the false positive rate was found to be $19 \%$ without excluding any cytological and histological diagnostic class (Table 3).

The distribution of histopathological diagnosis and smear test results (+/-) is shown in Table 4, excluding all cases with atypical cytology. As shown in Table 4, when atypical cytology are excluded, the sensitivity of the smear test was $69 \%$ based on the histopathological diagnosis. In other words, $69 \%$ of the cases with histopathological lesions were also found to have lesions based on the smear test. Similarly, selectivity was found to be $98 \%$. According to histopathological diagnosis, $98 \%$ of the lesion-free patients were also found to be lesion-free in the smear test. On the other hand, $89 \%$ of the patients with lesions detected by the smear test were also found to have lesions histopathologically, whereas $93 \%$ of the cases without lesion were also found histopathologically to be lesion-free. These are positive predictive and negative predictive values, respectively. Our overall accuracy rate is $93 \%$ and according to our histopathological diagnosis, which constitutes our reference test, our cervical smear screening test is capable of detecting $93 \%$ of the patients with lesions as having lesions and the patients without lesions as lesion-free.

\section{Discussion}

Since Pap smear test is a screening test for uterine cervical neoplastic lesions and histopathological evaluation, which is usually performed immediately after it, is a diagnostic test, it triggers both us and a high number of academicians to discuss the extent of reliability of smear test and to present a large number of regional correlation studies to the literature. In conclusion, the importance and reliability of smear test has been discussed by drawing attention to the similarities and differences in the literature. 
Table 2. Cyto-histopathological diagnosis comparisons of cases

\begin{tabular}{l}
\hline \multirow{2}{*}{ DIAGNOSES } \\
\cline { 2 - 9 }
\end{tabular}

Table 3. Cyto-histopathological comparison according to lesion positivity

\begin{tabular}{|c|c|c|c|c|}
\hline & \multicolumn{4}{|c|}{ Biopsy } \\
\hline \multirow{4}{*}{ 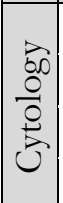 } & Number $(\%)$ & Negative & Positive & Total \\
\hline & Negative & $157(60,9 \%)$ & $11(4,3 \%)$ & $168(65,1 \%)$ \\
\hline & Positive & $49(19,0 \%)$ & $41(15,9 \%)$ & $90(34,9 \%)$ \\
\hline & Total & $206(79,8 \%)$ & $52(20,2 \%)$ & $258(100.0 \%)$ \\
\hline
\end{tabular}

Table 4. Statistical criteria of cervical smear test (Excluding cases with atypical cytology diagnosis)

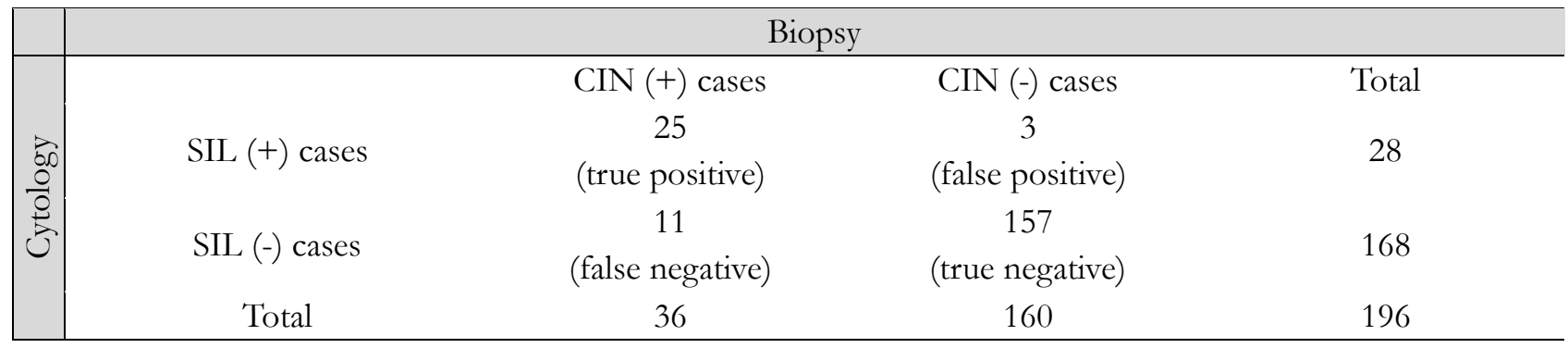

In one of these correlation studies, Sadik Sahin et al. compared the colposcopic biopsy results of patients with benign and ASC-US smears. While $88.6 \%$ of the colposcopic biopsy results of benign smear cases were reported with benign diagnoses, $10.7 \%$ were reported as CIN-1 and $1.7 \%$ were reported as CIN-2 and CIN-3. The biopsy results of patients with ASC-US smear result were reported as $69.2 \%$ benign, $15.4 \%$ CIN-1 and $15.4 \%$ CIN-2 and CIN-3, respectively (4).

In our study, the compatibility of patients with benign cytology with histological diagnosis was $93.5 \%$. This rate was similar to that of Sad1k Sahin et al. $(88.6 \%)$, but was slightly higher. On the other hand, $76.9 \%$ of the patients with smear ASC-US had a benign biopsy and although this rate was slightly higher $(69.2 \%)$ compared to the result obtained by Sadık Sahin et al. (69.2\%), close results were obtained.
Ozer Birge et al. reported in their study where they compared the results of Pap smear test in Sub-Saharan Africa with their subsequent histopathologies, that the cases with smear ASCUS were histopathologically diagnosed as $83.3 \%$ benign, 9.2\% CIN-1, 7.4\% CIN-2 and CIN-3 (5). As $76.9 \%$ benign and $7.7 \% \mathrm{CIN}-3$ patients were diagnosed histopathologically in our ASC-US smears, these results were similar to the results of our study. In said study, the benign histopathology diagnosis in ASC-H smears decreased to $25 \%$, while the rate of CIN-3 diagnosis increased to $50 \%$ (5). The high percentage $(63.6 \%)$ of our benign histopathology results in our group with ASC-H smear differs slightly with this study. LSIL smears were histopathologically diagnosed in the follow-up as $12.5 \%$ benign, $46.8 \%$ CIN-1, $41.2 \%$ CIN-2 and CIN-3, respectively. Benign histopathology diagnosis was not reported in $\mathrm{H}$ SIL smears and the histopathological diagnosis of $81.2 \%$ of the cases was CIN-2 and CIN-3 (5). 
Given the presence of $23 \%$ benign, $61.5 \%$ CIN-1 and $15.4 \%$ CIN-2 histopathological results in our L-SIL smears, the absence of benign histopathology in our H-SIL smears and in comparison to $91.7 \%$ of H-SIL + SCC histopathology, our study seems to have obtained similar results.

Similarly, in the same study (5), only $3 \%$ of the smears were positive, whereas in our study, this rate reaches about $34 \%$. Although the study has been carried out in a low sosyoeconomic place where black race lives and people get married in a young age, the multiple affair events occur only in those who are married more than once with their spouses due to their religious views. Low socioeconomics, white race, early age in marriage, smoking, multiple sexual partners etc. contributes to the development of cervical cancer, though not as much as HPV $(6,7)$. The factors that facilitate the development of cervical cancer may have created the difference between positive cytological diagnoses of studies done in different places. In smears with positive diagnosis, ASC-US class constitutes the highest percentage, which is similar to our study. In our study, ASC-US group was followed by ASC-H and L-SIL groups, respectively, in descending percentage in our positive cytology diagnostic group. On the other hand, in the study of Ozer Birge et al., it is followed by L-SIL and AGC groups.

Hüseyin Levent Keskin et al., reported in their study comparing 182 cervical smear histopathologies with cervical epithelial anomaly diagnosis that histopathological diagnosis was $79.2 \%$ benign, $4.9 \%$ CIN-2 and CIN-3 in ASC-US smears. The histopathological diagnosis of L-SIL smears was $12.5 \%$ CIN2- and CIN-3 and this ratio increased to $75 \%$ in H-SIL smears. This result was similar to the result obtained by Ozer Birge et al., and the results obtained in our study. The ASC-H smear groups in their study were diagnosed with $50 \%$ benign histopathology, more similar to our study. The smears in the AGUS group in their study were also diagnosed with $89.5 \%$ benign histopathology, similar to the $100 \%$ result in our study (8).

Remzi Attlgan et al., compared the conventional and fluid-based methods in cervical smears in their cyto-histopathology correlation studies and reported the histopathology of ASC-US smears in conventional smears as $35 \%$ lesion positive, whereas this rate was $60 \%, 73 \%$ and $100 \%$, respectively in ASC-H, L-SIL and H-SIL smears (9). Considering that the smears we evaluated were obtained by conventional method, these rates are
$23.1 \%, 46.4 \%, 77.9 \%$ and $100 \%$, respectively in our study and we can suggest a significant similarity between the studies.

In the light of the findings obtained as a result of the comparison of cyto-histopathology, when we included our atypically diagnosed smear classes in the false positive or true positive cytology groups based on the histology results, we calculated the ratio of false negative and false positive patients to all our patients as $4.3 \%$ and $19 \%$, respectively. These rates were found to be $5.3 \%$ and $3.5 \%$ without including atypically diagnosed cytology classes in false-positive cases in the study by Ozgur Mete et al., who correlated Pap smear and histopathology of 112 patients (10). Moreover, the number of patients diagnosed cytologically benign is six and compared to the number in our study (157), it is very low. In this case, while our false negative rates seem similar, it should be taken into consideration that the majority of false positives in our study are collected in the atypically diagnosed smear groups, even if our false positive rates seem quite high. Similar to the method used in this study, in our results that we obtained without placing atypical cytology into false positive or true positive classes, but also without deducting them from the total number of cases, false-negative cytology decreased to $1.2 \%$ and false-positive cytology decreased to $4.3 \%$ and their ratio to all cases gives similar results with this publication.

Similarly, Bruce A. Jones et al., reported that the total number of false negative and false positive cases was $16.5 \%$, excluding atypical smear cases, and considering that $62.7 \%$ of ASC-US smears and $52.6 \%$ of AGUS cases had positive histopathological diagnosis, it can be concluded that the false positivity values are concentrated in the cytological group with atypical diagnosis, similar to the case in our study (11). Similar to the method applied in the abovementioned study, when we exclude atypical cytology classes from the cases and calculate the ratio of our falsenegative and false-positive cases to the total number of cases, except those with atypical cytology, i.e. $7 \%$, and the result is less than half of the value in this publication.

Bruce A. Jones et al., reported smear test sensitivity as $89 \%$, selectivity as $65 \%$, and positive prediction as $89 \%$ by excluding cases with atypical cytology (11). In our study, when we exclude atypical classes, our results for these values are $69 \%, 98 \%$ and $89 \%$, respectively. They reported that when they included atypical cytology classes in the false positive and true positive cytology 
groups based on the histological results, the sensitivity increased to $91 \%$ and the selectivity decreased to $46.7 \%$ (11). Similarly, when we perform the same application, the sensitivity increases to $78 \%$ and the selectivity decreases to $76 \%$.

In addition, the most common causes for false negative and false positive smears were cytology sampling error $(85.2 \%)$ and estimated biopsy sampling error (94.6\%) (11). Although we did not go back to the materials of our false negative/positive cytology and try to find a reason in our study, considering the literature knowledge (12) linking the causes of false negative cytology to sampling error at $60 \%$ and screening error at $40 \%$, sampling errors seem to be the most common cause in the case of false negative and false positive cytology.

In their study where cyto-histopathological results of 61 cases were compared, Sezen Koçarslan et al., reported the sensitivity, selectivity, positive and negative predictive values as 76\%, 100\%, 100\% and $70 \%$, respectively, excluding atypical cytology classes in cervical smears and it is interesting that no false positive cytology cases were detected (13). It is stated that the ratio of ASC-US to all cervical cytology results should be around $4.4 \%$ in Pap smear screening test and that ASC-US/L-SIL ratio can be used as a control and this ratio should be around $1 / 1$ (14, 15). Similarly, in the literature, ASC/SIL ratio is stated to be important in the control of the use of atypical diagnostic groups in cytology, and this ratio is reported to be $0.87-4.5$, with values between two and three being the recommended values (16-18).

Ilknur Cetinaslan et al. reported in their study with 112 patients involving their cyto-histopathological correlation that the ASC/SIL ratio was 2.12 (19). In our study, this ratio was found to be acceptable (2.52) with 63/25 patients.

In conclusion, the value of cervical smear cytology, which cannot be replaced by another method as a screening test, will not decrease for many years. However, especially in our smear groups diagnosed with atypical cytology, histopathology diagnosis ranging from benign category to H-SIL category shows how vital the detection of HPV DNA and colposcopic examination can be especially in some patients, in addition to cervical smear screening and followup.

Acknowledgments: The authors are grateful to Prof. Dr. Siddik Keskin for the contribution of the article in statistical evaluation.

\section{References}

1. Cervical cancer early diagnosis and screening 2019, World Health Organization, https://www.who.int/cancer/prevention/diagno sis-screening/cervical-cancer/en/ (Accessed January 06, 2020).

2. Yapça ÖE, Delibaş İB, Onat E. Ardışık 3342 PapSmear Sonucunun Değerlendirilmesi: Retrospektif Çalışma. J Contemp Med 2015; 5: 234-238.

3. Nayar R, Wilbur DC. The Bethesda System for Reporting Cervical Cytology. Definitions, Criteria, and Explanatory Notes (3rd ed). New York: Springer, 2015.

4. Şahin S, Süer N, Yıldızhan R, Adalı E. Inflamasyon ve Ascus Smear Sonuçları Olan Olguların Kolposkopi ve Kolposkopik Biyopsi Sonuçlarının Karşılaştırılması. Göztepe Tıp Dergisi 2003; 18: 213-216.

5. Birge Ö, Demir F, Kayar I, et al. Cervical cytology screening in Sub-saharan Africa. Int J Curr Res 2016; 8: 25500-25504.

6. Rosai J., Ackerman L.V.: Tumors, Uterus-Cervix, Female Reproductive System. Surgical Pathology (9th ed). St. Louis: Mosby, 2004;(2), pp 15231568.

7. Wright TC, Kurman R.J, Ferenzy A. Precancerous Lesions of the Cervix. In: Kurman R.J. (ed). Blaustein's Pathology of the Female Genital Tract (5th ed). New York: Springer-Verlag 2002; 253324.

8. Keskin HL, Seçen Eİ, Taş EE, Kaya S, Avşar AF. Servikal smear sitolojisi ile kolposkopi eşliğinde servikal biopsi korelasyonu. Türk Jinekolojik Onkoloji Dergisi 2011; 3: 71-75.

9. Atılgan R, Artaş G, Kaplan S, et al. Thinprep ve konvansiyonel servikovajinal smearlerin histopatolojik sonuçlarının karşılaştırılması. Firat Med J 2015; 20: 19-24.

10. Mete Ö, Yavuz E, Tuzlalı S, et al. Retrospective study of 112 patients who had colposkopy-guided biopsy: Comparison of the cytology results with histology. Turk J Pathol 2007; 23: 33-37.

11. Jones BA, Novis DA. Cervical biopsy-cytology correlation; A college of American pathologists Q-probes study of 22439 correlations in 348 laboratories. Arch Pathol Lab Med 1996; 120: 523-531.

12. Wilkinson EJ. Pap smears and screening for cervical neoplasia. Clin Obstet Gynecol 1990; 33: 817-825.

13. Koçarslan S, Altunbaş BE, Güldür ME, Camuzcuoğlu A, Bitiren M. Servikal smear sitolojisi ile servikal biopsilerin sitohistolojik korelasyonu. Turkiye Klinikleri J Med Sci 2014; 34: 65-70.

14. Bacanakgil H, Bozkurt T, Çelik S, Dursun N, Pirusa S, Boran B. Servikal smear tarama profil ve 
sonuçları (4122 olgu). İstanbul Tip Dergisi 2008; 4: 1758-1781.

15. Jones BA, Davey DD. Qualty management in gynecologic cytology using interlaboratory comparison. Arch Patbol Lab Med 2000; 124: 672-681.

16. Nascimento AF, Cibas ES. The ASC/SIL ratio for cytopathologists as a quality control measure: A follow-up study. Am J Clin Pathol 2007; 128: 653-656.

17. Renshaw AA, Deschênes M, Auger M. ASC/SIL Ratio for Cytotechnologists: A surrogate marker of screening sensitivity. Am J Clin Pathol 2009; 131: 776-781.

18. Renshaw AA, Brimo F, Auger M. Surrogate indicators of sensitivity in gynecologic cytology: can they be used to improve the measurement of sensitivity in the laboratory?. Cytojournal 2009; 6: 19.

19. Türkman İÇ, Başsüllü N, Korkmaz $P$, et al. Patients with epithelial cell abnormality in PAP smears: Corellation of results with follow-up smears and cervical biopsies Turk J Pathol 2013; 29: 179-184. 